\title{
Introduction: Selected Papers from the 2017 Canadian Writing Centres Association Conference
}

Kathy Block

University of Manitoba

Clare Bermingham

University of Waterloo

Jordana Garbati

Wilfrid Laurier University

"We are, all of us, the languages that we speak; we cannot split off language from identity."-Dr. Frankie Condon, CWCA Keynote, 2017

Very recently, on April 9, 2018, the president of the University of British Columbia, Dr. Santa Ono, publicly apologized for the role that UBC played in Canada's residential school system. His apology follows the University of Manitoba's Statement of Apology and Reconciliation, which was issued in 2011 by its president, Dr. David Barnard. Both apologies name the harms that were done to Indigenous people and communities in the name of education (Barnard, 2011; Ono, 2018). They speak to the ways that residential schools made extraordinary efforts to disparage and wipe out Indigenous cultures as residential school children were robbed of their languages, their families, and their identities.

We include these institutions' apologies in this introduction because they address the past, the present, and the future of colonialism and reconciliation in Canada. Our 2017 CWCA conference took place on Canada's 150th anniversary, and these two themes threaded through the conference, connecting with other discussions about our students' diverse identities and histories that they bring to tutoring sessions in their languages, their stories, and their imagined future-selves. UBC's apology states that all universities bear responsibility for remaining silent in the face of injustice against and exclusion of Indigenous people. This serves as a critical reminder that, as faculty and staff of universities and colleges, we are always responsible for speaking out and for working towards equity and social justice in our work. 
Volume 28, 2018

http://journals.sfu.ca/cjsdw

What might working for equity and social justice look like in our centres? We return to Dr. Frankie Condon's keynote address, which is presented here as the first article. In "The Languages We May Be: Affiliative Relations and the Work of the Canadian Writing Centre," Condon challenges us to think in large ways about the transformative work that can happen in Canadian writing centres. Condon argues that writing centres are sites that can play a role in moving the university beyond its traditional role as knowledge preserver, towards a vision that reflects our collective commitment to equity and social justice. Transformation is possible where program administrators, instructors, and tutors have the courage to take risks and come to the writing centre as learners as much as teachers, engaging with student writers and the languages they bring. Condon calls us to consider the ways that identities are bound to language, to teach and support writers in ways that acknowledge and celebrate their languages, and in doing so, "dedicate ourselves to the nourishment of emerging relations" (p. 3).

When we began the process of co-editing a special issue for the $C J S D W / R$ nearly a year ago, our aim was to highlight the research that had been presented at CWCA's spring 2017 conference. The conference theme, "From Far and Wide: Imagining the Futures of Writing Centres," pushed presenters, writers, and attendees to consider how writing centres "make space for the multiple stories that writers have to tell" (CWCA, 2017). The call for papers for this conference asked that writing centre practitioners consider how we respect individual differences amid pressures such as budgets and challenging administrative contexts. The result of this call was a conference that was rich with research, discussion, problem-creation, and problem-solving. The following papers represent excellence in research, and as importantly, they represent initiatives and activities that question current practices, empower students, or take action on an important issue. They demonstrate the commitment of writing staff in Canada to making worthwhile contributions to the field of writing studies.

The second article in this section is Sharp and Rosenberg's "The Grammar of Social Justice: Gender Non-binary Pronouns and the Writing Centre." Here, the authors share how they responded when their series of posters displaying non-binary pronouns were repeatedly defaced. Contextualizing these events in the wider political climate, they ask, "How might the writing centre help to construct a transformative response that not only responds to individual events but which also aims at changing the underlying logics that make them possible?" (p. 3). In this case study, the authors show how Munoz's theory of disidentification and Rosculp's rhetoric of respect can become critical resources for action, which, for them, included building alliances across campus and finding ways to 
Volume 28, 2018

http://journals.sfu.ca/cjsdw

directly support and empower minoritized students. Their carefully considered responses to the defacement issue, including facilitated panels and campus consultations, show how social justice can be enacted in writing centres in productive ways.

Garbati and Brockett's “Students Speak Out: The Impact of Participation in an Undergraduate Research Journal" provides an example of how the writing centre can be a part of a transformative experience for undergraduate students. The authors discuss their research on an undergraduate research journal (URJ) at a Canadian university and show how students' involvement in a studentrun journal builds writing, teamwork, and time management skills in undergraduate authors, editors, reviewers, and management board members. Beyond skills, however, Garbati and Brockett provide an evidence-based argument that participating in an URJ can be transformative as it moves students beyond knowledge consumption and preservation to a position of agency as knowledge creators.

Finally, Nash, Dawson, and Gulozer's article, "Intersections Between Tutorial Engagement, Directive Feedback, and Critical Reflection," responds to the call for RAD research (i.e., research that is replicable, aggregable, and data-driven) issued by Driscoll and Purdue (2012), and furthers the current discussion of what effectiveness means in our work. In this article, we read about how three undergraduate students at an American liberal arts university used writing tutor feedback to revise their papers for an English course. Focusing on the impact of directive feedback, the authors show how these students responded to the input of a writing tutor in varied ways, sometimes using the feedback to improve the clarity and depth of a paper and sometimes misinterpreting or choosing not to incorporate feedback. This paper provides an up-close perspective on the kinds of strategies that Lori Salem (2016) discusses in her recent award-winning article, "Decisions...Decisions: Who Chooses to Use the Writing Center," making it is a timely and particularly relevant piece.

So what's ahead for writing centres and writing centre research? We continue to reflect, learn, and explore together as colleagues, and in concert with our students, building our practice and our research. We strive to stand beside our students as teachers, as coaches, and as allies. At CWCA's 2018 conference we will be challenged to think critically about the theme of politics and the writing centre. How does inquiry, knowledge, and dialogue propel action? Let's keep asking critical questions. Let's keep collaborating and building ideas together. We have a lot more to learn from each other.

\section{Acknowledgements}


Volume 28, 2018

http://journals.sfu.ca/cjsdw

We would like to thank the CJSDW/R for initiating this publication partnership with the Canadian Writing Centres Association (CWCA).

\section{References}

Barnard, D.T. (2011 October 27) University of Manitoba statement of apology and reconciliation to Indian residential school survivors. Retrieved from https://umanitoba.ca/about/media/StatementOfApology.pdf

CWCA. (2017) CWCA's 2017 conference: Call for papers. Retrieved from https://cwcaaccr.com/pastconferences/2017-conference/call-for-papers/

Driscoll, D. \& Perdue, S.W. (2012). Theory, lore and more: An analysis of RAD research in The Writing Center Journal, 1980-2009. The Writing Center Journal, 32(1), 11-39.

Ono, S. (2018 April 9) Statement of apology. Retrieved from https://president.ubc.ca/speeches/statement-of-apology/

Salem, L. (2016) Decisions... decisions: Who chooses to use the writing center? Writing Center Journal, 35(2), 147-171. 